\title{
Trade, Technology and Labour Markets-Empirical Controversies in the Light of the Jones Model
}

\author{
Michael Pflüger \\ DIW Berlin and IZA
}

\begin{abstract}
The deterioration of the income and employment position of unskilled workers in the OECD since the 1980s is a well-documented fact. The debate about the causes of this development is dominated by two competing hypotheses, "North-South Trade" ("globalisation") and technological progress. Several empirical methodologies have been used to identify and quantify the importance of these two explanations: factor content analyses, consistency checks, regression analyses and numerical methods. However, no consensus has been achieved so far and there is considerable methodological controversy. This paper uses Jones's (1965) exposition of the standard trade model as analytical backbone to identify and settle the sources of disagreement, to provide a synthesis of existing results, to derive new insights, and to provide a comprehensive assessment of the aforementioned empirical methodologies.
\end{abstract}

- JEL Classifications: F16, F21; J31

- Key words: North-South trade, Technology, Wage inequality, Unemployment

\section{Introduction}

It is a well-documented fact that the income and employment position of unskilled workers in the OECD has deteriorated since the 1980s (OECD, 1997; IMF 1997). The debate about the causes of this development is dominated by two competing hypotheses. Some economists, e.g. Wood (1994) and Leamer (1998),

\footnotetext{
*Corresponding address: Dr. Michael Pflüger, DIW Berlin, Königin-Luise-Straße 5, 14195 Berlin. Tel (Fax): 030-89789-154(114) E-mail: mpflueger@diw.de.

(C2004-Center for International Economics, Sejong Institution, All Rights Reserved.
} 
argue that 'North-South Trade' ('globalisation') has played a decisive role. Others, e.g. Lawrence (1996), Bhagwati (1998) and Krugman (1995a), argue that biased technological progress is the main culprit. Four empirical methodologies have been used to identify and quantify the importance of these two explanations: factor content analyses, consistency checks, regression analyses and numerical methods. So far these studies have come up with remarkably diverse results. Hence, there is no consensus yet (Cline, 1997; Collins, 1998b). Moreover, there is considerable controversy about the theoretical legitimacy of the empirical methodologies. Heavy objections have been raised notably against the factor content approach. This state is surprising as most reasoning is cast - explicitly or implicitly - in terms of factor proportions theory. Hence, a rigorous application of this theory should settle the sources of disagreement. This is the starting point of this paper. It uses Jones's (1965) representation of Heckscher-Ohlin-Samuelson (HOS) theory as analytical backbone to put the aforementioned empirical methodologies under scrutiny. The paper focuses on their theoretical consistency with the HOS model and on the causes for the diversity of results. The unified theoretical treatment has several payoffs: The roots of the controversies are identified and a synthesis of recent results in a common framework can be provided. Some new insights are obtained. Finally, a comprehensive assessment of the strengths and weaknesses of the empirical methodologies is provided. The structure of the paper is as follows. Section 2 reviews the model and its implications for the debate about trade, technology, wages and employment. Section 3 takes up factor content analyses. Consistency checks are explored in section 4 . Section 5 turns to regression analyses. Section 6 addresses numerical studies. Section 7 provides an overall assessment.

\section{Trade and Technology in the Jones Model}

The Jones (1965) model is covered in almost any trade textbook (e.g. Bhagwati et al., 1998). For the purpose of reference, the model's equations are summarised in Table 1. The production side of the (say) Northern economy is characterised in (1)-(4). A high-tech-good and a low-tech-good (index: $i=H, L$ ) are produced for perfectly competitive markets with skilled and unskilled labour (index: $j=H, L$ ) under constant returns to scale. Let $X_{i}$ denote outputs, $H_{i}$ and $L_{i}$ inputs of skilled and unskilled labour, $p_{i}$ prices and $w_{j}$ factor prices. The economy has fixed endowments of skilled labour, $H$, and unskilled labour, $L$. Input coefficients, $a_{j i}$, 
Table 1. The Jones Model (1965)

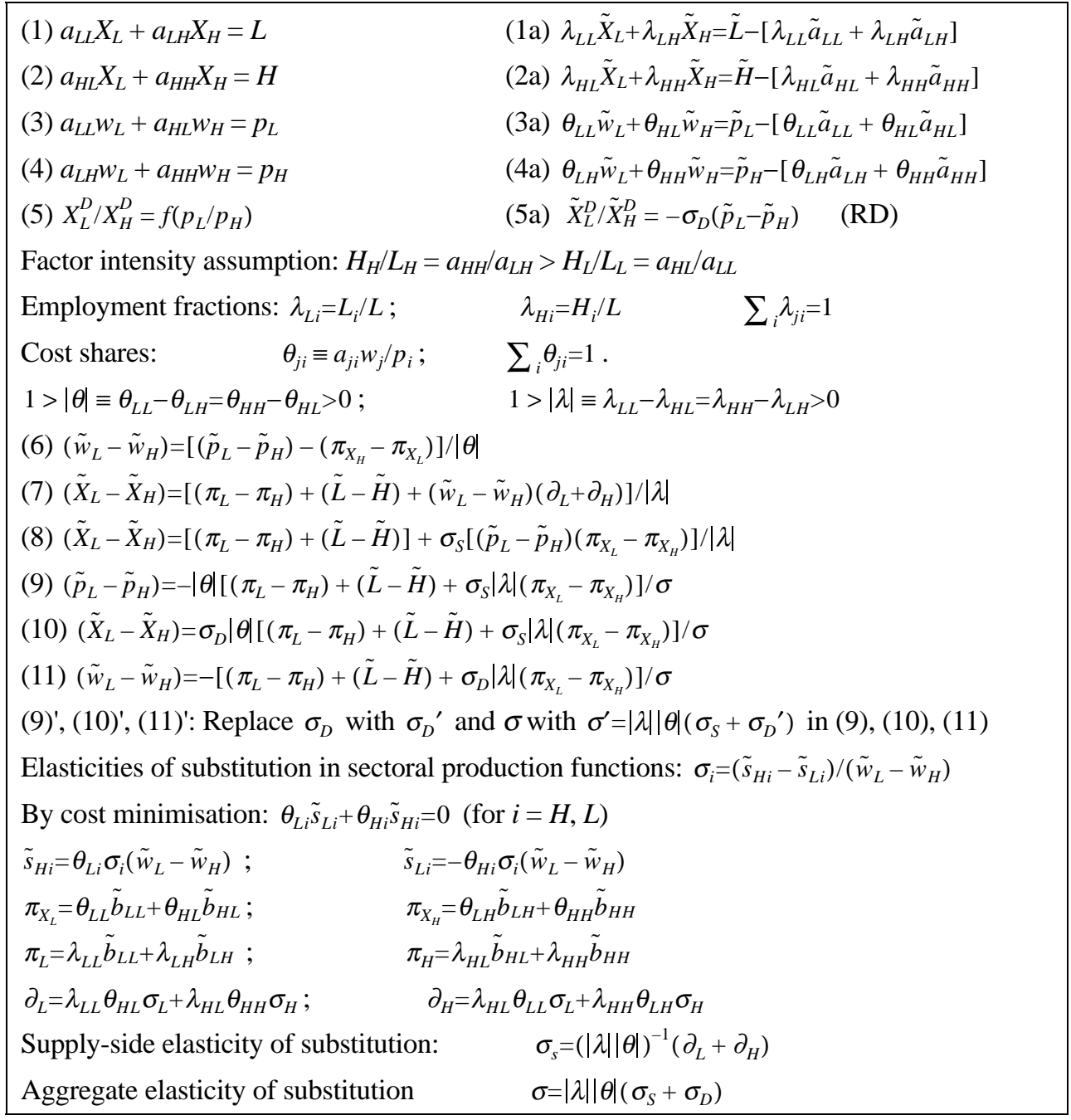

depend on the factor price ratio, $w_{L} / w_{H}$, and the level of technology, $\tau$. By assumption, the high-tech good is produced more skill-intensively than the lowtech good for any factor price ratio. Eqs. (1) and (2) describe factor market clearing. Competitive pricing in the two industries is given in (3) and (4). Preferences of the representative household are assumed to be homothetic. Therefore, the relative demand for low-tech goods, $X_{L}^{D} / X_{H}^{D}$ is a function, $f(\cdot)$, of relative prices in (5). For the purpose of comparative static analysis the model is log-linearised. Relative changes are indicated by a tilde (e.g. $\left.\tilde{X}_{i} \equiv d X_{i} / X_{i}\right)$. Eqs. (1a)-(5a) are the log-linearised counterparts to (1)-(5). Cost and employment 
shares are given by $\theta_{j i}$ and $\lambda_{j i}$, respectively. Changes in the input coefficients can be split in two components: $\tilde{a}_{j i}=\tilde{s}_{j i}-\tilde{b}_{j i}$. The first characterises the change in $a_{j i}$ when factor prices change and the second the direct effect of technological progress: $\delta a_{j i} l \delta \tau<0$. Hence, $\tilde{b}_{j i}>0 . \sigma_{D}$ is the elasticity of substitution in relative demand (RD) in (5a).

Central results of the model are contained in (6)-(11). The Stolper-Samuelsonrelationship (6) between goods prices, the sectoral growth rates of total factor productivity $\left(\pi_{X_{L}}\right.$ and $\pi_{X_{H}}$ ), and factor prices follows from (3a) and (4a). The Rybczynski-relationship (7) between factor supplies, the rates of factor saving technological progress $\left(\pi_{L}\right.$ and $\left.\pi_{H}\right)$, and output levels is derived from (1a) and (2a). The relative supply relationship (8), obtained from (6) and (7), shows the effect of factor endowments and technology on relative outputs for given goods prices. $\sigma_{S}$ measures the supply-side elasticity of substitution. The effect of factor endowments and technology on goods prices stated in (9) is obtained from (5a) and (8). $\sigma$ is the 'aggregate elasticity of substitution'. Equations (10) and (11) indicate how relative outputs and relative wages, respectively, are affected by factor endowments and technology. They follow from (8) and (9) and from (6) and (9), respectively.

What are the effects of trade and technological change in this framework? Turn to trade first. Suppose there is a second economy, the South, with the same technology and preferences as the North but a larger relative endowment of unskilled labour. Hence, by (9), in autarky, the low-tech good is relatively cheaper in the South. Opening up trade between the two economies must then raise the relative price of high-tech goods in the North. This induces a magnified fall in the

Table 2. Effects of Technological Progress on the Wage Differential

\begin{tabular}{|c|c|c|c|}
\hline & ...low-tech sector & ...high-tech sector & $\begin{array}{c}\text {...both sectors at the } \\
\text { same rate }\end{array}$ \\
\hline $\begin{array}{c}\text { Unskilled labour } \\
\text { saving progress in ... }\end{array}$ & $\begin{array}{l}\tilde{b}_{L L}>0 \\
\text { SMOPEC: } \uparrow \\
\text { LOPEC: ? }\end{array}$ & $\begin{array}{l}\tilde{b}_{L H}>0 \\
\text { SMOPEC: } \downarrow \\
\text { LOPEC: } \downarrow\end{array}$ & $\begin{array}{l}\tilde{b}_{L L}=\tilde{b}_{L H}>0 \\
\text { SMOPEC: } \uparrow \\
\text { LOPEC: ? }\end{array}$ \\
\hline $\begin{array}{c}\text { Skilled labour saving } \\
\text { progress in ... }\end{array}$ & $\begin{array}{l}\tilde{b}_{H L}>0 \\
\text { SMOPEC: } \uparrow \\
\text { LOPEC: } \uparrow\end{array}$ & $\begin{array}{l}\tilde{b}_{H H}>0 \\
\text { SMOPEC: } \downarrow \\
\text { LOPEC: ? }\end{array}$ & $\begin{array}{l}\tilde{b}_{H L}=\tilde{b}_{H H}>0 \\
\text { SMOPEC: } \downarrow \\
\text { LOPEC: ? }\end{array}$ \\
\hline Neutral progress in... & $\begin{array}{l}\tilde{b}_{L L}=\tilde{b}_{H L}>0 \\
\text { SMOPEC: } \uparrow \\
\text { LOPEC: ? }\end{array}$ & $\begin{array}{l}\tilde{b}_{L H}=\tilde{b}_{H H}>0 \\
\text { SMOPEC: } \downarrow \\
\text { LOPEC: ? }\end{array}$ & $\begin{array}{l}\tilde{b}_{L L}=\tilde{b}_{H L}=\tilde{b}_{L H}=\tilde{b}_{H H}>0 \\
\text { SMOPEC: } 0 \\
\text { LOPEC: } 0\end{array}$ \\
\hline
\end{tabular}


relative wage of the unskilled by (6) and increases the relative supply of the hightech good by (8) in the North.

Technological change can take on a myriad of forms in this model. First, one or several of the coefficients $b_{j i}$ may change. Second, technological progress may occur world-wide or in one region only. Usually it is assumed that technological progress occurs in the North and is not immediately transferred to the South. Finally, the North may be a small price taking economy (SMOPEC) as in Leamer (1994), or it may be a large open economy (LOPEC) affecting the prices on world markets as in Krugman (1995b).

It is immediate from (6) that, in the SMOPEC-case, the relative wage is governed by $\pi_{X_{H}}-\pi_{X_{L}}$, the "sector bias" or "differential industry effect". The effects of technological progress limited to a Northern LOPEC can be derived as follows (Landmann and Pflüger 1998): Replace the relative demand curve of the North $R D$ with the curve $R D^{\prime}$ which is obtained by adding the net relative demand of the South to the relative demand of the North (see the appendix for an illustration). Combining this curve $R D^{\prime}$ with (6) and (8) gives solutions for relative product prices, outputs and the factor prices which mimic equations (9), (10) and (11) except that $\sigma_{D}{ }^{\prime}$, which indicates the elasticity of the $R D^{\prime}$-curve, now replaces $\sigma_{D}$ and that $\sigma^{\prime}=|\lambda||\theta|\left(\sigma_{S}+\sigma_{D}{ }^{\prime}\right)$ replaces $\sigma$. These are stated in (9)'-(11)'. The effect of technological progress can be taken from (11)': the relative wage is affected by both, the "factor bias" or "differential factor effect", $\pi_{L}-\pi_{H}$, and the "sector bias". Table 2 summarises the effects of different forms of technological progress on the wage differential. In the LOPEC-case, only unskilled labour saving technological progress in the high-tech sector is unambiguously unfavourable for the unskilled. In all other cases, the effect is either ambiguous, positive, or neutral. Clearly, the claim that technological progress widens the wage-differential in general is wrong.

So far, the model presupposes flexible wages. However, for a number of reasons - e.g. social security systems, trade union policies, minimum wage laws -, relative wages are rigid in Europe (Wood 1994; Krugman 1995a). The effects of trade and technology shocks when relative factor prices are fixed are straightforward (Krugman 1995a): the skill group who would experience a falling relative wage with flexible wages now suffers from unemployment. Based on this analytical framework, the different methodological approaches can now be put under scrutiny. 


\section{Factor Content Analysis}

\section{A. The Basic Methodology}

The factor content method is a popular tool among labour economists to evaluate the quantitative effect of trade or immigration on wages. It has its theoretical roots not in a general equilibrium trade model but in a simple model of relative supply and demand on a labour market and has therefore come under attack from trade theorists. ${ }^{1}$ The method proceeds in two steps (Wood, 1994; Collins, 1998b). In a first step, the amount of skilled and unskilled labour embodied in the imports and exports of an economy are calculated. Let $L_{T}$ and $H_{T}$ denote the net factor content of trade (trade index: $T$ ). The terms $\Delta X_{i, T}^{D}-\Delta X_{i, T}$ capture (changes in) exports and imports. The net factor content of trade is obtained by weighting these with the input coefficients at the prevailing goods and factor prices:

$$
\begin{aligned}
& L_{T}=\left(\Delta X_{L, T}^{D}-\Delta X_{L, T}\right) a_{L L}+\left(\Delta X_{H, T}^{D}-\Delta X_{H, T}\right) a_{L H} \\
& H_{T}=\left(\Delta X_{L, T}^{D}-\Delta X_{L, T}\right) a_{H L}+\left(\Delta X_{H, T}^{D}-\Delta X_{H, T}\right) a_{H H}
\end{aligned}
$$

The effective factor supplies, $L_{e, T}$ and $H_{e, T}$, are derived by adding the net factor content of trade to the initial supply, $L_{e, T}=L+L_{T}$ and $H_{e, T}=H+H_{T}$. In a second step, a constant aggregate elasticity of substitution, say $c_{1}$, is specified in order to relate the effective relative factor supply to the wage differential: $w_{L} / w_{H}=c_{0}\left(H_{e} / L_{e}\right)^{\left(1 / c_{1}\right)}\left(c_{0}, c_{1}=\right.$ constant $)$. Therefore, changes in effective supplies induce changes in the wage differential according to:

$$
\Delta \ln \left(w_{L} / w_{H}\right)=c_{1}^{-1} \Delta \ln \left(H_{e} / L_{e}\right) .
$$

\section{B. Results for North-South Trade}

Factor content analyses have predominantly come up with the result that NorthSouth trade has been of minor importance for the deterioration of the relative

\footnotetext{
${ }^{1}$ In a different context, the factor content concept is undisputed: The "factor content proposition" states that a country's exports embody mainly factors which are in ample supply while the imports embody mainly the scarce factors. See e.g. Helpman and Krugman (1985).
} 
income and employment position of the unskilled in the OECD. ${ }^{2}$ For two reasons, results differ across studies. First, operational differences such as the measurement of skills (e.g. by years of schooling or by occupational activities) and the selection of industries matter. Second, there is some disagreement about the specification of $c_{1}$, the aggregate elasticity of substitution. Sachs and Shatz (1998) obtain a rather large trade effect because they select a value which is low in comparison to most other studies. ${ }^{3}$ These conventional factor content analyses have come under attack from Wood $(1994,1995,1998)$ who notes that "the smallness of the estimated impact in the North (...) sits uncomfortably with the seemingly far larger impact in the South" (Wood, 1994: 9). Wood has three objections on the conventional practice. First, he argues that the input coefficients prevailing in the North should not be used to estimate the labour market impact of manufacturing imports from the South because these goods are no longer produced in the North (they are "noncompeting"). According to Wood, using Northern input coefficients in statistical sectors corresponding to the imports of the South produces a downward bias. For this reason, Wood adjusts these coefficients upwards. Second, he claims that import competition induces technological progress which is biased against unskilled labour. Third, Wood argues that the expansion of trade in services has repercussions on the non-traded goods sector and therefore on labour markets. On the basis of rule-of-thumb adjustments and back-of-the-envelop estimates, Wood concludes that North-South trade has reduced the relative demand for unskilled labour by some $20 \%$, which is about the tenfold of conventional estimates. Wood's adjustments can be criticised as being arbitrary, an insight elaborated on below (see 3.3.3). Moreover, the inherent logic of his arguments can be disputed. If imports are indeed non-competing, it is hard to believe that they can displace jobs. It is also unconvincing that strong incentives to implement new low-skilled labour-saving technologies should result from non-competing imports (Burtless, 1995: 812).

Apart from Wood's critique, three objections have been raised against the factor content method. First, it has been criticised that the factor content method takes trade flows as exogenous whereas in fact they are endogenous (e.g. Leamer, 1994;

\footnotetext{
${ }^{2}$ See the influential studies by Murphy and Welch (1991), Katz and Murphy (1992), Borjas, Freeman and Katz (1992, 1996, 1997), Sachs and Shatz (1994, 1998), Baldwin and Cain (1997) and the surveys by Katz (1992), Baldwin (1994), Wood (1994), Burtless (1995), Cline (1997) and Collins (1998b).

${ }^{3}$ Sachs and Shatz (1998: 227) choose values in the range from 1/3 to $1 / 2$ whereas labour economists typically choose a value at around 3/2 (See Katz and Murphy (1992: 68f.) and Collins (1998: 33)).
} 
Bhagwati 1998). Hence, trade flows are not only affected by a reduction in trade barriers but by all the "primitives" of the model. Striking misjudgements may result if this is disregarded. Second, it has been argued that the factor content approach lacks a coherent theoretical basis. In particular it has been questioned whether eq. (13) can be rationalised by a general equilibrium model. Third, it has been claimed that the method produces biased results when wages are rigid. These objections are now taken up in turn.

\section{Methodological Issues I: Flexible Factor Prices}

\section{What Does the Factor Content Tell US?}

Bhagwati and Dehejia (1994: 49) produce examples which are intended to show that the factor content may produce absurd results. In the following, two of these are taken to explain why, contrary to their stipulation, meaningful results are obtained with the factor content method. However, the results require careful interpretation. ${ }^{4}$ Think of a small open economy of the type characterised in section 2 which, at some point in time $t$, selects its production along its transformation curve and its consumption along the world price line. Suppose that in $t+1$ preferences of the representative household have shifted in favour of the import good. Production is unaffected by this shift. However, the new consumption point involves more of the import good and less of the export good. Goods prices have not changed and by (6) the wage differential must be the same as in $t$. However, because of the enlarged trade triangle, the factor content of trade indicates that the effective relative supply of low skilled labour has risen. Would a factor content analysis therefore not counterfactually have to conclude that the wage differential must have developed to the disadvantage of the unskilled? Suppose next that not only a preference shift has taken place in $[t, t+1]$ but that trade barriers have fallen, too, so that the relative price of imports has fallen, giving rise to a new world price line. What does the factor content of trade us tell us when two (or more) shocks occur at the same time?

A procedure suggested by Panagariya (2000) is helpful for clarification. Consider the time interval $[t, t+1]$. Use $T$ as an index for trade equilibria observed in $t$ and $t+1$. The actual change in the wage differential can approximated by: (i) $\Delta \ln \left(w_{L} / w_{H}\right)_{t, t+1}^{T}=\ln \left(w_{L} / w_{H}\right)_{t+1}^{T}-\ln \left(w_{L} / w_{H}\right)_{t}^{T}$. The observed trade equilibria can be compared with hypothetical autarky equilibria (indexed by $A$ ). For these it is

\footnotetext{
${ }^{4}$ The following draws on Baldwin (1999), Deardorff (2000), Leamer (2000) and Panagariya (2000).
} 
counterfactually assumed that trade is impossible. The hypothetical change in the relative wage in $[t, t+1]$ can be approximated by: (ii) $\Delta \ln \left(w_{L} / w_{H}\right)_{t, t+1}^{A}=$ $\ln \left(w_{L} / w_{H}\right)_{t+1}^{A}-\ln \left(w_{L} / w_{H}\right)_{t}^{A}$. The change in relative factor prices induced ("caused") by "trade" is then obtained by subtraction: (iii) $\Delta \ln \left(w_{L} / w_{H}\right)_{t, t+1}^{T}-\Delta \ln \left(w_{L} / w_{H}\right)_{t, t+1}^{A}=$ $\Delta \ln \left(w_{L} / w_{H}\right)_{t+1}^{T, A}-\Delta \ln \left(w_{L} / w_{H}\right)_{t}^{T, A}$. From this it becomes clear that if we are able to determine how factor prices would differ if the economy maintained trade instead of being in autarky in $t$ and $t+1$, i.e. if we are able to determine $\Delta \ln \left(w_{L} / w_{H}\right)_{t+1}^{T, A}$ and $\Delta \ln \left(w_{L} / w_{H}\right)_{t}^{T, A}$ (which the factor method purports to be able to using (13)), then we are also able to quantify the effect of trade on relative factor prices. Clearly, comprehensive information about the "primitives" is necessary to determine the non-observable (hypothetical) autarky equilibria, however.

This procedure can be used to clarify the questions raised by the two simple examples. In the first example, the observed change in the relative wage (i) is nil. However, the preference shock changes the hypothetical autarky equilibrium. This movement along the transformation curve is associated with a change in relative goods prices in autarky which, by (6) changes factor prices. This effect is captured by (ii). Due to the openness of the economy ("because of trade"), this adjustment of the relative wage is prevented, as can be seen from (iii), and is correctly indicated by the factor content method. For the second example, (i)-(iii) can again be used to explore the quantitative impact of trade (openness) on the relative wage. Trade (the change in the trade triangle) now reflects both shocks, the preference shock and the reduction of trade barriers. The effect of the "globalisation shock proper" (i.e. the reduction in trade barriers) therefore differs from the overall effect deriving from openness. With comprehensive information to determine the hypothetical autarky equilibria (i.e. knowledge of technologies, preferences, factor endowments and their changes), the shocks can be performed one after the other. Thereby the relative wage changes associated with openness and with the "globalisation shock proper" can be identified. One may well argue that the information required by this method is simply not available in practice. In this sense, the critics of the approach are justified to insist that to make the "globalisation shock proper" responsible for the observed change in factor prices is correct only when the other "primitives" have happened to remain constant.

\section{Theoretical Consistency With the HOS Trade Model?}

The factor content approach has also come under attack because it seemed not be based on the general equilibrium logic of the standard trade model. However, 
in a classic paper, Deardorff and Staiger (1988) have shown that its consistency with the HOS-model when technology and preferences are Cobb-Douglas. This result has been generalised, recently.

Deardorff and Staiger proceed in two steps. Their procedure is useful to clarify the recent generalisations, too (Panagariya, 2000). In a first step, they show that for a HOS-model with diversified production, corresponding to every trade equilibrium there is an "equivalent" autarky equilibrium in the following sense: if the economy's factor endowment is adjusted by the net factor content of trade (as described in 3.1), there is a competitive autarky equilibrium which, at the trade equilibrium's goods prices, provides the same consumption vector. This result doesn't require restrictions on technology and preferences. It can be rationalised as follows. ${ }^{5}$ With linear-homogeneous technologies and the appropriate factor endowment, domestic production can simply be scaled up. This is also an equilibrium for consumers because goods prices are unchanged and domestic production provides the necessary factor income to purchase these goods. Equivalent autarky equilibria are useful because they allow to infer the factor prices prevailing with trade. In particular, it is possible to compare the factor prices prevailing in two trade equilibria by comparing the equivalent autarky equilibria. In the second step, Deardorff and Staiger establish that a systematic relation between factor prices and factor endowments exists for a closed Cobb-Douglas economy. This result and its generalisations can easily be established with the Jones-model. Abstracting from technological progress, (11) becomes: $\left(\tilde{w}_{L}-\tilde{w}_{H}\right)=$ $-(\tilde{L}-\tilde{H}) / \sigma$. This shows that relative factor prices and endowments are related by $\sigma=|\lambda||\theta|\left(\sigma_{S}+\sigma_{D}\right)$, the aggregate elasticity of substitution, in a closed HOSeconomy. This is not a replication of (13) yet, because $\sigma$ is an endogenous variable in (11). However, in two cases (13) and (11) are consistent. The first case is a CESeconomy where utility and production functions are CES with identical elasticities (Deardorff, 2000; Panagariya, 2000). When $\sigma_{L}=\sigma_{H}=\sigma_{D}=$ const. $\equiv c_{2}$, the supplyside elasticity of substitution is: $\sigma_{S}=c_{2}[1-|\lambda||\theta|] /|\lambda||\theta|$. Then, the aggregate elasticity of substitution is given by $\sigma=c_{2}$, proving the claim. The Cobb-Douglas case is covered for $\sigma=1$. The second case is when, initially, the economy is autarkic and when trade is so small that marginal analysis applies (Krugman,

\footnotetext{
${ }^{5}$ The following arguments draw on Panagariya (2000) and on the exposition of the factor proportion theory in Helpman and Krugman (1995). An analytical proof is contained in Deardorff and Staiger (1988).
} 
1995b; 2000): A reformulation of (12a) and (12b) gives: ${ }^{6} L_{T} / L=\tilde{L}_{e}=\lambda_{L L}\left(\tilde{X}_{L, T}^{D}-\tilde{X}_{L, T}\right)$ $+\left(1-\lambda_{L L}\right)\left(\tilde{X}_{H, T}^{D}-\tilde{X}_{H, T}\right)$ and $H_{T} / H=\tilde{H}_{e}=\lambda_{H L}\left(\tilde{X}_{L, T}^{D}-\tilde{X}_{L, T}\right)+\left(1-\lambda_{H L}\right)\left(\tilde{X}_{H, T}^{D}-\tilde{X}_{H, T}\right)$. Then, $\tilde{L}_{e}-\tilde{H}_{e}=|\lambda|\left[\left(\tilde{X}_{L, T}^{D}-\tilde{X}_{H, T}^{D}\right)-\left(\tilde{X}_{L, T}-\tilde{X}_{H, T}\right)\right]$. Using (5), (8), and (6), and taking into account that endowments do not change, it follows that $\tilde{L}_{e}-\tilde{H}_{e}=-|\lambda||\theta|$ $\left(\sigma_{S}-\sigma_{D}\right)-\left(\tilde{w}_{L}-\tilde{w}_{H}\right) c$ which replicates (11) and, hence, proves the claim.

\section{Extensions and Limitations}

By the two-step procedure used above, the factor content method can be shown to be consistent with the HOS-model when it is amended for non-traded or intermediate goods and trade deficits (Deardorff, 2000; Panagariya, 2000). When there is a trade deficit, the interpretation of the result requires some care. Take a SMOPEC which begins to run a trade deficit at some point in time. The new trade triangle reveals a change in the net factor content of trade indicating a change in relative factor prices by (13). However, factually there is no change in goods and factor prices. As Deardorff (2000: 80) elaborates, the factor content analysis now indicates the change in factor prices “... that would have occurred if the increase in expenditure had been accompanied by, say, increased import tariffs and export subsidies sufficient to prevent any change at all in the quantities of trade."

The factor content approach has limitations, the most serious, arguably, being the assumption of diversified production. With non-competing imports, equivalent autarky equilibria no longer exist because it is not profitable to produce these goods at the prevailing prices even if this were technically feasible. Deardorff (2000) suggests a modified concept of an equivalent autarky equilibrium. His idea is to give the economy a "dose of Hicks-neutral technical progress" just sufficient, to make the (non-producing) import-competing sector profitable. As before, the factor endowments have to be adjusted by the net-factor content of trade (measured at those input coefficients which would prevail, if the import-competing sector were just profitable). Then, one could proceed as before, i.e. compare the factor price change associated with the shift between two trading equilibria by comparing these modified equivalent autarky equilibria. Is there, however, a systematic relation between exogenous factor supplies and Hicks-neutral technological progress on factor prices in an autarkic economy? From (11) and

\footnotetext{
${ }^{6}$ To see this, replace the $\Delta$ 's with $d$ 's, rewrite the input coefficients (e.g. $\left.a_{L L}=\left(L_{L} / L\right)\left(L / X_{L}\right)=\lambda_{L L}\left(L / X_{L}\right)\right)$, and take into account that consumption and production coincide in the initial autarky equilibrium, $X_{i, T}^{D}=X_{i, T}$.
} 
using $\tilde{b}_{L L}=\tilde{b}_{H L}>0$ for Hicks-neutral technological progress: $\left(\tilde{w}_{L}-\tilde{w}_{H}\right)=$ $-\left\lfloor(\tilde{L}-\tilde{H})+\left(\lambda_{L L}-\lambda_{H L}\right)\left(1-\sigma_{D}\right) \tilde{b}_{L L}\right\rfloor / \sigma$. An inspection immediately reveals that when preferences are Cobb-Douglas $\left(\sigma_{D}=1\right)$, Hicks-neutral technological progress has no influence on relative factor prices. As in step 2 of the previous analysis, in order to obtain a constant aggregate elasticity of substitution it has to be assumed that the utility and production functions exhibit the same constant elasticity of substitution. Therefore, in the present case they have to be equal to one (Cobb-Douglas-case). If the elasticity of substitution deviates from one, a forecast based on the net-factor content of trade alone will be erroneous as a further inspection reveals: if $\sigma_{D}>1$, the relative wage of the unskilled would be higher than stipulated; if $\sigma_{D}<1$, a downward-adjustment of the wage differential is necessary. This result is helpful to evaluate Woods (1994) upward adjustment. With non-competing imports, this is correct only when $\sigma_{D}<1$. The practical relevance of this new concept has been questioned by Panagariya (2000): The production technologies of "non-competing imports" are unobservable in the importing country. Even if they were known, it would be difficult to find out the amount of Hicks-neutral technical progress which would make their production profitable. There are further limitations apart from the diversification issue. The assumption of identical and constant elasticities of substitution is arbitrary. Moreover, the concept of an equivalent equilibrium collapses when technologies exhibit increasing returns because the input coefficients become scale-dependent in this case. Similar problems arise, when trade induces technical progress, adjustments in factor endowments or preferences.

\section{A Different Theoretical Rationalisation}

Deardorff and Hakura (1994: 92) anticipate that an "extreme specific factors model" can provide a rationalisation for (13) apart from HOS. Sachs and Shatz (1998) work out such a model. They assume that two tradables, a final good and an intermediate, and one non-traded good are produced in the North. Intermediates require inputs of sector specific capital and skilled and unskilled labour. Skilled labour and capital are complements in the production of the final good which also requires intermediates as inputs. Liberalisation of the foreign investment regime in the South makes it profitable to relocate some capital. By implication, labour released from the intermediate goods sector in the North can only be reemployed in the non-traded goods sector. The change in the relative wage is accordingly determined by the elasticity of substitution in this sector which gives rise to (13). 
However, the assumptions required to defend (13) do not seem to be weaker than those needed in HOS-theory.

\section{Methodological Issues II: Fixed Factor Prices}

The factor content could also be used to infer how much unemployment results from trade, when wages are inflexible as in Europe. However, an application of the factor content approach leads to erroneous results with rigid wages (even for specifications that are consistent with the flex-wage HOS-model). The estimates are downward-biased because the employment loss caused by trade (the difference between production and consumption) is magnified by an induced income loss which is ignored by the factor content approach. This insight can be clarified with the help of figure 1 borrowed from Krugman (1995a).

The endowments of skilled and unskilled labour in "OECD-Europe" are depicted in a standard box diagram. In autarky, $L$ and $H$ are fully embodied in production and consumption, as shown by $F_{A}$. As shown in section 2, some unskilled workers become unemployed when there is trade with the South. Let $F_{P}$ depict those factors which remain employed after this trade shock. The factors embodied in consumption are determined by the intersection $\left(F_{C}\right)$ of an income line through $F_{P}$ with slope $\left(-w_{L} / w_{H}\right)$ and the diagonal, which is the income expansion path with homothetic preferences. The net-export of skilled labour is then given by $F_{C} F_{B}$ and the net-import of unskilled labour by $F_{P} F_{B}$. Obviously, the actual employment loss, $F_{A} F_{P}$, is much larger as indicated by the factor content of trade because of the leftward-shift of the income-line (the initial income line

Figure 1. Factor content analysis with fixed factor prices

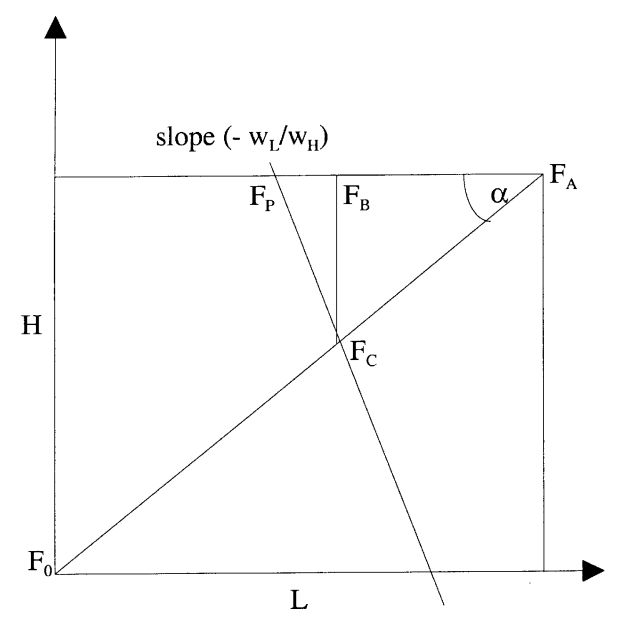


through $F_{A}$ is not drawn). However, the actual employment loss, $F_{A} F_{P}$, is easy to quantify. It can be decomposed into two parts. $F_{P} F_{B}$ is the net-import of unskilled labour obtained by a factor content calculation. For $F_{A} F_{B}$ we have: $F_{A} F_{B}=F_{C} F_{B} \tan \alpha$ where $\tan \alpha=H / L$ and $F_{C} F_{B}$ is obtained from the factor content analysis. Krugman performs back-of-the envelope calculations for OECD-Europe on the basis of this analysis: net-imports of unskilled labour and net exports of skilled labour (as shares of OECD-GDP) are at 0.82 and 0.41 , respectively. The relative endowment (unskilled/skilled) is at 1.5 . Then, $1.43 \%$ of the unskilled become unemployed by North-South trade. This is much larger than what an estimate based on the conventional factor content approach would predict. However, it clearly is only a small fraction of the unemployment that has build up in Europe since the 1970's.

\section{E. The Bottom Line}

The factor content approach is based on a simple framework of relative demand and supply on the labour market. It is easy to implement, which may partly explain its popularity. Under particular assumptions, the approach is theoretically consistent with a HOS-model with flexible prices. Among the assumptions that must be met are constant return technologies, homothetic preferences, diversification in production, and the assumption that trade does not induce changes in technology, preferences and endowments. If these conditions are met, and (a) if the production and utility functions exhibit a joint constant elasticity of substitution, or, (b), if trade flows are small enough and the economy is initially autarkic, the factor content approach is consistent with HOS. This approach may alternatively be defended by appeal to a specific factors model. When the wage differential is fixed, a conventional factor content analysis leads to a systematic underestimation of the employment loss. It is open to debate whether the assumptions which are necessary to give the method a sound theoretical foundation are overly strong or not. Turning to the results obtained for North-South trade, most studies indicate only a minor impact on the relative wage. Larger estimates are obtained when very low values are chosen for the aggregate elasticity of substitution or for nonconventional upward adjustments of the factor content. 


\section{Consistency Checks}

\section{A. Methodology}

Consistency checks use the restrictions that the HOS-model imposes on the data to identify qualitatively which of the two competing hypotheses - trade or technology shocks - can be made responsible for the negative demand shift for unskilled labour in the OECD area. So far, most studies have focused on relative goods prices and on sectoral factor intensities. In the following, these are reviewed and some other indicators as well.

\section{B. Relative Prices}

It follows from (6) that relative prices are central in the transmission of trade shocks to factor prices as Bhagwati has stressed time and again. Inspecting quarterly U.S. import and export prices for 1982-1989, Bhagwati (1991) has found that the former have risen faster than the latter. This "anti-Stolper-Samuelson movement of prices" (Bhagwati, 1995) casts considerable doubt on the NorthSouth-trade hypothesis. However, this analysis is only a crude test because the terms-of-trade of the U.S. are dominated by the prices of oil and other commodities (Cline, 1997: 93). A better test is obtained by focussing on sectoral prices of unskilled and skilled intensive goods. A voluminous literature has used sectoral price data to establish "descriptive evidence" and to perform regressions of the following type: ${ }^{7}$

$$
\tilde{p}_{i}=\alpha_{0}+\alpha_{1} h_{i}^{m}+\alpha_{2} D+\xi_{i}
$$

The proportional variation of sectoral output prices (the index $i$ now indicating sectors) is the left-hand variable in (14). $h_{i}^{m}$ is some measure of the skill-intensity of production at the start of the analysis. A dummy-variable, $D$, may be used to highlight a sector of special interest. $\xi_{i}$ is an error term. $\alpha_{0}$ and $\alpha_{2}$ are estimates of the inflation trend and the influence of some special industry. The sign of $\alpha_{1}$ is of central importance: if the trade hypothesis were to hold, sectoral prices should increase with rising skill-intensity. Methodologically, regression equation (14) is only indirectly supported by the model of section 2. In particular, it is not backed by zero profit conditions such as (3a) and (4a).

\footnotetext{
${ }^{7}$ See Lawrence and Slaughter (1993), Sachs and Shatz $(1994,1998)$ and Slaughter (1998a).
} 
The evidence on prices "turns out to be rather disappointing" (Wood, 1995: 73). A brief review of some of the most prominent studies reveals the sources of disagreement. Most work has been done for the U.S. Lawrence and Slaughter (1993) confirm Bhagwatis finding. For a selection of manufacturing industries in the period 1980-1989, they obtain weakly negative coefficients, $\alpha_{1}$, both for import and export prices. They proxy the skill-intensity by distinguishing (unskilled) "nonproduction workers" and (skilled) "production workers" and do not use a dummy. Additionally, Lawrence and Slaughter calculate employment weighted price indices for manufacturing imports and exports which reveal the following: if import and export prices are weighted by the employment shares of production workers in the industries, their increase is larger as when they are weighted by the employment shares of nonproduction workers. According to Lawrence and Slaughter this proves that the relative price of goods which use unskilled labour intensively has fallen. Sachs and Shatz (1994) obtain an inverse result. They use the share of production workers in the industries (in relation to their total employment) as an inverse proxy for the skill intensity. Moreover, they specify a dummy for the computer industry because they take the measurement of prices in this industry as extraordinarily unreliable (given the productivity developments). For 1978-1989 and excluding the computer industries, Sachs and Shatz find that price increases were smaller in those industries which employed high fractions of production workers (unskilled). In a follow-up study for 19781995 and using value-added prices in addition to conventional output prices, they confirm their former result (Sachs and Shatz, 1998). Leamer (1998: 167ff) presents "descriptive evidence" based on the Bartelsman and Gray (1996) industry data set for 1960-1992. Based on price movements in the apparel and textile sectors (relative to overall producer prices), Leamer documents that three periods have to be distinguished for low-skill intensive goods: their relative price has fallen slightly in the 60's, fallen strongly in the 70's and has remained fairly constant in the 80 's. This result and other plots, for the 80 's confirm the inconclusive picture obtained by the two aforementioned studies. Most interesting is the clear verdict for the 70's, i.e. the time span before the wages of the skilled and unskilled strongly drifted apart. ${ }^{8}$ Kruegers (1997) study for the U.S. draws on

\footnotetext{
${ }^{8}$ This result opposes a finding by Lawrence and Slaughter (1993: 204) who report: “..the terms of trade were basically flat in the 1980s (and actually declined in the 1970s)." See also table 4 in Lawrence and Slaughter (1993: 203).
} 
(15), too. For 1989-1994, he obtains a positive correlation between changes in goods prices and the relative use of skilled to unskilled labour. His result is robust with respect to the measurement of skills (i.e. occupational activity or years of schooling) and is qualitatively consistent with the result obtained by Sachs and Shatz (1998). The study by the OECD (1997) is an attempt to obtain a comparative picture for OECD trade with emerging economies. ${ }^{9}$ The study finds that the average import price of import competing industries relative to the price of export sectors has decreased in almost every country in the OECD. For Germany, the study diagnoses a clear increase in relative export prices from 1980 to 1990 (OECD, 1997: Table 4.6). For the same time period, Lawrence (1994: 18ff; 1996: 56ff) obtains an inverse result. The price of "manual-worker-intensive products" has not declined according to employment-weighted price indices and according to his regression analyses based on (14). Fitzenberger (1999) documents that Germany's terms of trade have deteriorated from 1970 to 1981 and have improved (first slightly, then stronger) thereafter. Neven and Wyplosz (1999) find no significant changes in the terms of trade of France, Germany, Italy and England. In correspondence with the OECD's results, Haskel and Slaughter (1999: 22f) document a relative price increase for high-skill intensive goods in England in the 80's.

\section{Sectoral Skill Intensities}

The evolution of sectoral skill intensities, $h_{i} \equiv H_{i} / L_{i}$, has also been used to shed light on the two competing hypotheses. From section 2 it follows that skill intensities evolve according to:

$$
\tilde{h}_{i}=\tilde{a}_{H i}-\tilde{a}_{L i}=\sigma_{i}\left(\tilde{w}_{L}-\tilde{w}_{H}\right)+\left(\tilde{b}_{L i}-\tilde{b}_{H i}\right) \quad(i=H, L)
$$

The trade hypothesis by (6) implies a rising wage differential with the consequence that skill intensities must decrease in all industries by (15). A large number of studies documents that skill intensities have risen in almost all sectors in the U.S. ${ }^{10}$ Krugman and Lawrence (1994) take this as clear discriminating

\footnotetext{
${ }^{9}$ Exceptions are Australia, The Netherlands and Norway, according to this study. The study classifies Argentina, Brasil, Chile, China, Taiwan, Hong Kong, India, Indonesia, Korea, Malaysia, Singapur and Thailand as "emerging economies".

${ }^{10}$ See Bound and Johnson (1992), Katz and Murphy (1992), Berman, Bound and Griliches (1994), Lawrence and Slaughter (1993), and the discussion in Katz (1992), Krugman and Lawrence (1994: 49) and Freeman (1995).
} 
evidence against the "North-South hypothesis" and in favour of a technological explanation. For three reasons this judgement is premature, however. First, in order to be more than a measure of our ignorance, the technology hypothesis has to be specified as section 2 has shown: only particular forms of technological progress imply a rising wage differential. A similar conclusion can be drawn with respect to the evolution of sectoral skill intensities. The following example is revealing. It is often claimed that technological progress is “...neutral across sectors but biased against unskilled workers." progress of this type occurs in both sectors at the same rate (i.e. $\tilde{b}_{L L}=\tilde{b}_{L H}>0$; $\left.\tilde{b}_{H L}=\tilde{b}_{H H}=0\right)$. Then, by (15), taking wages initially as given, the skill intensities must rise. Given goods prices, this type of technological progress raises the relative wage of the unskilled (by (6), see table 1) which reinforces the rise in skill intensities. However, it comes with the side-effect that the relative wage moves in favour of the unskilled. Only the LOPEC-case allows for the possibility (not the necessity) of a simultaneous increase of skill intensities and the wage differential. ${ }^{12}$ Second, in their attack against the North-South trade hypothesis, Krugman and Lawrence impose the ceteris paribus restriction that all other things were constant. This was certainly not the case in the relevant time span in the U.S. (Cline, 1997: 91). In particular the supply of high-skilled workers has increased and had to be absorbed by the labour market. This supply shock works in favour of the relative wage of the unskilled by (11) and raises skill intensities by (15). Third, in a HOS model with fixed input coefficient and, hence skill intensities, the Stolper-Samuelson mechanism is operative, too (Leamer, 1994). Surely, given the evidence, it is much harder to reject the hypothesis that the sectoral skill intensities remain constant (which is plausible in the short- to medium run) than that they must have fallen.

\section{Other Indicators}

The debate about "trade vs. technology" has drawn on further indicators. Krugman and Lawrence (1994: 48f), argue that employment in high-techindustries which are favourably affected by a globalisation shock must have risen

\footnotetext{
${ }^{11}$ This citation is from Wood (1995: 75). Baldwin (1994) and Krugman (1995b) draw on this type of progress. ${ }^{12}$ The change in the wage differential is unfavourable for the unskilled, if $\sigma_{D}^{\prime}<1 /|\theta||\lambda|$ (by (11)).
Using (11) and (15) gives: $\tilde{h}_{i}=\tilde{b}_{L i}\left[1-\sigma_{i}\left(1-\sigma_{D}^{\prime}|\lambda||\theta|\right) / \sigma^{\prime}\right]$
} 
relative to employment in low-tech-industries. However, this was not the case: “...skill-intensive industries showed at best a slight tendency to grow faster than those in which blue-collar employment was high" (Krugman and Lawrence, 1994: 49). Again, this does not seem to be enough to reject the trade hypothesis in favour of the technology hypothesis. This is particularly so because the type of technological progress which is often seen as the main culprit has unexpected counterfactual implications: by (10), sector-neutral unskilled labour saving technical progress leads to a relative expansion of the low-tech sector. Moreover, this expansion of the low-tech industries in the North would counterfactually reduce the volume of North-South trade.

How difficult it is to identify the "true" shock on the basis of qualitative evidence is also revealed by inspecting Wood's $(1994 ; 1995)$ conjecture that the inverse correlation between industry employment in the OECD countries and the growing import penetration in these sectors is so strong that causality of trade is almost established. If relative wages are rigid which holds true for a great number of countries in his sample, particular forms of biased technological progress (and not only "globalisation") imply growing imports from the South. Take the example of sector neutral unskilled labour saving technological progress, again. According to (11) this releases unskilled labour if $\sigma_{D}{ }^{\prime}<1 /|\theta||\lambda| .{ }^{13}$ By (7), the relative output of the high-tech-sector will rise and (with an elastic offer curve of the rest of the world) this implies that the trade quantities must rise.

Consistency checks have been directly applied to the technology hypothesis, too. Lawrence and Slaughters (1993: 199ff) investigation of Hicks-neutral progress biased towards the high-tech-sector yields contradictory findings, however. According to Table 1, this type of progress implies that the wage differential moves in favour of the skilled. According to (15), when goods and hence factor prices are given, this type of technological progress implies that skillintensities must decline. However, this is contradicted by the general upskilling found for the U.S. Moreover, regressions similar as (14) run by Lawrence and Slaughter find a negative correlation between this type of technical progress and the input ratio of nonproduction to production workers. Evidence for this type of technological progress is obtained by an analysis of employment-weighted

\footnotetext{
${ }^{13}$ Note that this is the same condition as the one found in our previous inquiry of the conditions under which this type of technical progress leads to a lower relative wage (LOPEC-case) when wages are flexible.
} 
technical progress rates, however. Other studies (e.g. Berman et al., 1994) document a positive correlation between skill intensities and technological indicators. Clearly, these correlations do not prove causality. Moreover, there is anecdoctic evidence for "defensive innovation activities" in low-skill intensive import competing sectors (Wood, 1995: 76).

\section{E. The Bottom Line}

Consistency checks use the qualitative implications of the HOS-model to identify the roots of the negative demand shift for unskilled labour which has occurred in the 1980s. No clear picture has emerged from these studies. Not even a consensus on key, stylised facts' has been established. The diversity of findings is partly explained by operational reasons - e.g. the measurement of skill classes and the selection of industries. A deeper reason for the failure of consistency checks is that the key variables do not follow a simple explanation, according to the data. Rather they seem to be jointly determined by a more than one shock. An important message emerging from our analysis is that it is premature to reject the trade hypothesis on the ground that it has failed to meet one or two consistency checks and to accept the competing hypothesis instead. This renders the technology hypothesis tautological and makes it serve as a "measure of our ignorance", once again (Leamer, 2000). More fundamentally, once well-specified, the technology hypothesis may have counterfactual implications itself.

\section{HOS-Based Regression Analysis}

\section{A. Methodology}

Quantitative estimates of the effect of trade and technological progress on factor prices can be obtained by econometric regressions which draw on the zero profit conditions of the HOS-model. Let the index $i$ characterise an industry as in section 4.2. Then, for an arbitrary number of inputs, $j$, eqs. (3.a) and (4a) generalise to: $\tilde{p}_{i}=\sum_{j} \theta_{j i} \tilde{w}_{j}+\sum_{j} \theta_{j i} \tilde{a}_{j i}$. Total factor productivity in sector $i$ is now given by: $\pi_{X_{i}}=\sum_{j} \theta_{j i} \tilde{b}_{j i}=-\sum_{j} \theta_{j i} \tilde{a}_{j i}{ }^{14}$ Using the redefinition $\tilde{T} \tilde{F} \tilde{P}_{i} \equiv \pi_{X_{i}}$ the following fundamental relation is obtained:

\footnotetext{
${ }^{14}$ This uses $\sum_{j} \theta_{j i} \tilde{s}_{j i}=0$ which follows by cost minimisation.
} 


$$
\tilde{p}_{i}=\sum_{j} \theta_{j i} \tilde{w}_{j}-\tilde{T} \tilde{F} \tilde{P}_{i}
$$

With cross-section data about price changes, $\tilde{p}_{i}$, total factor productivity growth, $\tilde{T} \tilde{F} \tilde{P}_{i}$, and given initial factor shares, $\theta_{j i}$, (16a) can be used to derive those factor price changes, $\tilde{w}_{j}$, which are consistent with the zero profit conditions. A more sophisticated approach takes into account that in industrialised countries, the share of intermediate goods in value added amounts to $50 \%$ or more (e.g. Slaughter, 1998a). Eq. (16a) should therefore be generalised to $\tilde{p}_{i}=\sum_{j} \theta_{j i} \tilde{w}_{j}+\sum_{z} \gamma_{z i} \tilde{p}_{z}-\tilde{T} \tilde{F} \tilde{P}_{i}$ where it is assumed that each final good can be used as an input in the production of the other goods. The cost share of intermediate good in the production of the final good $i$ is given by $\gamma_{z i}$. Rearranging this last equation yields

$$
\tilde{p}_{i}-\sum_{z} \gamma_{z i} \tilde{p}_{z} \equiv \tilde{p}_{w i}=\sum_{j} \theta_{j i} \tilde{w}_{j}-\tilde{T} \tilde{F} \tilde{P}_{i}
$$

where $p_{w i}$ are value-added prices in industry $i$. So far, the bulk of studies has centred on the U.S. and has used the intermediate goods version (16b) of the zero profit conditions. Two approaches can be distinguished. They are dealt with in the next two sections.

\section{B. Separating the Effect of Technology and "Globalisation"}

\section{Leamer's Pioneering Work}

Leamer (1998) has pioneered the attempts to separate the quantitative effects of technological progress and globalisation on factor prices. Building on (16b), he specifies two regression equations. A first equation of the form $\tilde{T} \tilde{F} \tilde{P}_{i}=\sum_{j} \theta_{j i} \tilde{w}_{j}$ (plus error term) abstracts from changes in value-added prices. As a result, an estimate of factor price changes, $\tilde{w}_{j}(\tau)$, is obtained, which is explained by the development of total factor productivity (indexed by $\tau$ ). This accords with the SMOPEC-case of section 2. A second regression equation of the form $\tilde{p}_{w i}=\sum_{j} \theta_{j i} \tilde{w}_{j}$ (plus error term) abstracts from technological progress. This regression establishes the factor price changes, $\tilde{w}_{j}(g)$, which are explained by the observed changes in value-added prices. Leamer subsumes all factors which potentially cause changes in value-added prices (e.g. a reduction in trade barriers, developments in the rest of the world which influence the terms of trade, etc..) under the heading "globalisation" (indexed by $g$ ). The total factor price changes which are consistent with the zero profit equations are obtained from adding up the two separate effects, $\tilde{w}_{j}=\tilde{w}_{j}(\tau)+\tilde{w}_{j}(g)$. The share of factor price changes 
attributable to "globalisation factors" is then given by: $\left|\tilde{w}_{j}(g)\right| /\left(\left|\tilde{w}_{j}(\tau)\right|+\left|\tilde{w}_{j}(\tau)\right|\right)$.

It follows from the analysis in section 2, that this procedure is invalid in the LOPEC-case, because shocks which originate in a large economy have an effect on relative goods prices on world markets. In order to apply the analysis to the (large open) American economy, Leamer proceeds as follows. He assumes that total factor productivity growth reduces value-added prices by a "pass-through" factor $\lambda$ which is assumed to be equal for all industries. The change in value-added prices can then be decomposed in two components, $\tilde{p}_{w i}=\tilde{p}_{w i}(\tau)+\tilde{p}_{w i}(g)$. The first component is the result of total factor productivity growth, $\tilde{p}_{w i}(\tau)=-\lambda \tilde{T} \tilde{F} \tilde{P}_{i}$, and the second component gives the effect that can be attributed residually to "globalisation": $\tilde{p}_{w i}(g)=\tilde{p}_{w i}-\tilde{p}_{w i}(\tau)=\tilde{p}_{w i}+\lambda \tilde{T} \tilde{F} \tilde{P}_{i}$. The effects attributable to total factor productivity growth and to "globalisation", respectively, depend on the "pass-through"-coefficient. The SMOPEC-case, $\tilde{p}_{w i}(\tau)=0$, obtains for $\lambda=0$ (" $0 \%$ pass-through"). For a "100\% pass-through", total factor productivity growth is completely reflected in lower value-added prices: $\tilde{p}_{w i}(\tau)=\tilde{T} \tilde{F} \tilde{P}_{i}$. The technological effect on factor prices can then be derived from the definition $\tilde{p}_{w i}(\tau) \equiv \sum_{j} \theta_{j i} \tilde{w}_{j}(\tau)$ $-\tilde{T} \tilde{F} \tilde{P}_{i}$ and from $\tilde{p}_{w i}(\tau)=-\lambda \tilde{T} \tilde{F} \tilde{P}_{i}$. It is given by $(1-\lambda) \tilde{T} \tilde{F} \tilde{P}_{i}=\sum_{j} \theta_{j i} \tilde{w}_{j}(\tau)$. Using the definition $\tilde{p}_{w i}(g) \equiv \sum_{j} \theta_{j i} \tilde{w}_{j}(g)$, the globalisation effect on wages follows residually: $\tilde{p}_{w i}+\lambda \tilde{T} \tilde{F} \tilde{P} \tilde{P}_{i}=\sum_{j} \theta_{j i} \tilde{w}_{j}(g)$.

Leamers results are not uniform. Using a high-wage/low-wage operationalisation for the two skill groups, he finds growing wages to be mandated in the 60s and 80s and decreasing wages in the 70s, in the U.S.. The globalisation effect has been particularly strong against the unskilled in the 70s. In the 60s and 70s moderate wage growth is mandated for the high-wage group, in the $80 \mathrm{~s}$ a fall in their wage is mandated. The decomposition is strongly affected by the "pass-through"-coefficient. Using the production worker/non-production worker distinction to measure skill leads to the results which are qualitatively consistent with the previous operationalisation of skills in the 60s and 70s. However, in the 80's, depending on the "pass-through"-assumption, a negative total effect is mandated for the unskilled and a positive total effect for the skilled, implying a rise in the skill differential. In the 80s, globalisation works in favour of a rising wage differential for all "pass-through"coefficients. With $100 \%$ pass-through, a rising skill differential is mandated in the 70 s. With a $0 \%$ pass-trough, an inverse result emerges, however. Overall, the globalisation effect dominates technology (with exception when the production/nonproduction worker classification is used and when the pass through is $0 \%$ ).

Leamers results show that "globalisation" may have played an important (if not 
the dominant) role in the deteriorating position of the unskilled. However, they are open to three objections. First, "globalisation" is treated as the residual factor. This is as problematic as the usual inverse procedure. Second, only if the economy under consideration is small, is Leamers approach convincing (i.e. with a "pass-through" rate of $0 \%$ ). In a LOPEC, technological progress affects the worlds goods prices as is clear from section 2. Using a "pass-through"-assumption is problematic because not only total factor productivity growth (the "sector bias") but also the "factor bias" is of relevance for goods prices (see (9)). Third, one can raise objections against the assumption that total factor productivity growth raises value-added prices only. Taking input-output relations into account, one would expect productivity improvements in one sector to have price spillovers on other sectors.

\section{Other Works in Leamers Tradition}

Krueger (1997) has performed regressions for the U.S. and the period 19891994 which show that "globalisation" mandates a rising wage differential. However, Krueger's results have been disputed by Slaughter (1998a) who extends Kruegers database of 150 SIC-manufacturing industries to all to 450 industries and thereby obtains an inverse result. Fitzenberger (1999) analyses West-Germany in the period 1975-1990. He selects 36 (mainly manufacturing) industries from the 58 of the West-German national income accounts and, in contrast to most of the literature, forms three skill classes. His regressions show that total factor productivity growth has been beneficial for the groups with high skills and low skills and for capital owners. The gain for the group with medium skills is small. Fitzenberger finds that "globalisation" mandates wage increases for the medium skill group only. For the other factors decreasing prices are mandated. Overall Fitzenberger concludes that his results are consistent with the view that low-skilled workers have been negatively affected by international trade whereas those with medium and high skills have mostly been (positively) affected by technology. Haskel and Slaughter (1999) use a two-step procedure to decompose trade and technology effects for England. First, they follow Leamers methodology. They find that total factor productivity growth mandated an insignificant decline of the relative wage of the skilled work-force. Globalisation factors, in contrast, mandate an increasing wage differential and were the major force behind the rise in inequality in the $1980 \mathrm{~s} .{ }^{15}$ In a second step, they use regression analysis to uncover the causes of

\footnotetext{
${ }^{15}$ In a different study, Haskel and Slaughter (1998) obtain the result that the rising wage differentials in the U.S. and in England can be explained by the "sector bias" of technological progress.
} 
relative price changes and of total factor productivity growth. They use these two as dependent variables and choose variables such as union density, the degree of product market competition, the number of innovations, computerisation and international price changes as independent variables. They find that English goods prices are not very sensitive to pressure from import prices so that "how much such price changes are due to trade is an open question for future work" (1999: 4).

\section{Alternative Approaches}

In their regression analysis for the U.S., Baldwin and Cain (1997) draw on (17b), too. Unlike Leamer (1998) they do not incorporate technological progress in their regression equation. They proceed in two steps. In a first step, they estimate "mandated factor price changes" and they analyse whether these are consistent with the observed factor price trends. In a second step, they inquire into the possible causes of the goods price movements using complementary evidence about trade, technology and factor endowments. They use input-output-data, proxy qualification by years of schooling and analyse three time periods. For 1968-1973 a compression of the wage differential is mandated and best explained by an increasing supply of skilled labour. For 1973-1979 a reduction of the wage differential is mandated, too. Complementary evidence reveals that factor supply effects have not been strong in this period and that trade must have acted to increase the wage differential. For 1979-1991 an increasing wage differential is mandated. Trade seems to have been favourable for the unskilled. Therefore, Baldwin and Cain conclude that the deteriorating wage position of the unskilled must have been due to technological developments.

The regression analysis in Feenstra and Hanson (1997) is inspired by their outsourcing model (Feenstra and Hanson, 1996) which is an extension of the HOS-model in the sense that one final good is produced with a continuum of intermediate goods whose production requires capital and skilled and unskilled labour as primary inputs. According to this model, outsourcing shows up in the data as total factor productivity growth. Feenstra and Hanson proceed in two steps to find out the change in the wage differential which can be explained by outsourcing. In a first regression equation, they relate the observed growth in total factor productivity to alternative measures of outsourcing (trade in intermediate goods in a narrow and a wide sense) and a technology measure. In a second step, Feenstra and Hanson follow Leamer's methodology and identify the wage changes that are mandated by the measure of outsourcing. They find that 
outsourcing plays a large role in generating wage inequality for a $0 \%$-pass-through rate. However, some coefficients are insignificant. Moreover, with a different pass-through assumption, the results are no longer unanimous and technological change becomes of greater importance.

Harrigan and Balaban (1999) use an econometric general equilibrium model for the U.S. in which technologies, factor endowments and goods prices explain the developments of outputs and factor prices. The theoretical backbone of their approach is the revenue-function which states the maximal production value for an economy given technologies, goods and factor prices. From the partials of a quadratic approximation of this function, they obtain their regression equations. Harrigan and Balaban take American goods prices to be endogenous variables. Therefore, they have to use instrumental variables such as the degree of competition from the world market and demographic factors to determine goods prices. They find that capital accumulation and relative price changes - in particular an increase in the price of skill-intensive non-traded goods - had a strong influence on the skill premium in the U.S. They take their results to be "consistent with an explanation of relative wage movements (...) because of international competition". However, they "can not say with confidence why relative prices changed" (Harrigan and Balaban, 1999: 20).

\section{The Bottom Line}

Methodologically, HOS-regression studies are book-keeping procedures relating goods prices, factor prices and total factor productivity growth. Neither for the U.S. nor for other countries have uniform results been found. In particular, no clear picture emerges for the $80 \mathrm{~s}$, confirming a finding obtained from consistency checks. Two approaches have been used to disentangle globalisation and technology effects. Leamer analyses price movements and total factor productivity growth in industry sectors. He uses an arbitrary pass-through assumption to account for the fact that technological progress in large economies spills into product prices. Baldwin and Cain, on the other hand, disregard technological progress and try to use complementary evidence to explain movements in goods prices. The selection and weighting of industries, data aggregation, the measurement of skills and different pass trough assumptions are responsible for the diversity of results obtained in the literature. Some studies find that price movements have found to be important for factor price changes. However, it is unclear whether these are due to international competition or other 
factors.

\section{Numerical Analyses}

\section{A. Methodology and Krugmans Pioneering Work}

Another method to obtain quantitative evidence is to calibrate the HOS-model using specified functions and numerical values for the parameters. Krugman (1995a) has taken the lead in the trade and wages debate. Krugman takes the model of section 2 serious. He takes the OECD to be the North and an aggregate of newly industrialising economies (NIEs) to be the South and he chooses the early 70s as the starting point of North-South trade. Preferences and technologies are assumed to be Cobb-Douglas. The cost shares are set at $\theta_{H H}=2 / 3$ and $\theta_{H L}=1 /$ 3. Unskilled labour is chosen to be the numéraire, the initial wage rate of the skilled is chosen to be $w_{H}=w_{L}=1$. Endowments are selected to be $L=60$ and $H=80 .{ }^{16}$ Hence, $a_{H i}=\theta_{H i}, a_{L i}=1-\theta_{H i}, p_{H}=p_{L}=1$, and from (1) and (2), $X_{H}=100$ and $X_{L}=40$, initially. For consistency reasons, the budget share of high-tech goods, 1$\gamma$, must equal $p_{H} X_{H} /\left(p_{H} X_{H}+p_{L} X_{L}\right)=5 / 7=0.714$. Krugman undertakes the experiment of $3 \%$ rise in the relative wage of the skilled (so that $w_{H}=1.03$ ). The new values for prices and outputs are: $p_{H}=1.02, p_{L}=1.01, X_{H}=102.8$ and $X_{L}=37.2$. The share of the high-tech-good in value added increases to 0.736 . Therefore, $2,2 \%$ of the OECD's production value can be exported to the NIEs. This coincides approximately with the observed statistical value. From this, one can conclude that North-South-trade is responsible for $3 \%$ of the increase of the wage differential, a significant if quantitative small effect. Another important result of this analysis is that the associated increase in the relative price of high-tech goods of $1 \%$ is so small that it can hardly be distinguished from statistical "noise".

\section{B. Small Scale vs. Large Scale Models}

With modern techniques it is possible to extend the basic HOS-model in any dimension and yet to obtain numerical results. However, with increasing scale of the model it becomes increasingly difficult to understand the roots of the results. There is no agreed-upon answer on the critical question, "How big should the baby be?" (Bliss, 2000). Krugman's small-scale modelling approach has been

\footnotetext{
${ }^{16}$ The skilled amount to $40 \%$ of the OECD labour force. Krugman transforms one unit of skilled labour into two units of unskilled labour to have a skilled wage of unity, initially.
} 
extended by a number of authors. For alternative parameterisations of Krugman's model, Cline (1997) and Francois and Nelson (1998) have obtained the result that a $1 \%$ increase of the relative price of high-tech goods may lead to increases of the wage differential which are slightly higher than Krugmans 3\%-result. Francois and Nelson (1998) find, that the effect may be drastically higher, when intermediate goods are incorporated in the model. Lawrence and Evans (1996) have incorporated a non-traded goods sector in the standard model. They analyse a "future scenario" in the sense of an expansion of U.S. trade which causes the import competing sector to disappear. With Cobb-Douglas-technologies and preferences they obtain a decline of the relative wage of the skilled by $7.5 \%$. With substitution elasticities smaller than one, they obtain even stronger effects on the wage differential. The small-scale modelling technique has also been followed by Pflüger (2001) who incorporates a non-traded sector, and a third factor, internationally mobile capital, into a SMOPEC version of model of section 2 in order to analyse the employment and wage effects of two globalisation shocks on West-Germany, a relative price shock and an interest rate shock. The model is numerically implemented for West-Germany in 1980 on the base of two data sets, the input-output tables and employment data from a random sample of social security accounts. Several scenarios are studied: flexible wages with and without diversification and a minimum wage. For two reasons, this study indicates no strong effects on unemployment and/or the wage differential in West-Germany, overall: first, the smallest fraction of the labour force is employed in the import competing industries and, second, small price or interests rate shocks suffice to drive the economy into specialisation, so that possibly strong malign StolperSamuelson effects cannot materialise. Abrego and Whalley (2000) criticise the $2 \times 2$-SMOPEC model on two grounds. Different parameterisations can be identified which generate the same change in the relative wage as the outcome of a simultaneous shock in prices and in technology. This is an immediate implication of (6). Second, they criticise that full specialisation in production occurs with little change in prices. As an alternative model, they propose that imports are substitutes in demand for non-traded goods. This has the result that the effect of trade on wages is greatly reduced. The essential conclusion offered by Albrego and Whalley is that the choice of the structural model matters for the decomposition of observed wage changes in trade and technology components.

A number of studies use large-scale models. Cline (1997) develops a model with 13 regions, 5 sectors and 3 factors (skilled and unskilled labour and capital). 
He explores the counterfactual change in the relative wage of the skilled if trade barriers remained at their 1973 level. The result is that the relative wage of the skilled would be about 7-10\% lower. Another result concerns the role of the nontraded goods sector. If this sector (which accounts for about $60 \%$ of the production value in the U.S.) were eliminated, the relative wage of the skilled would rise by over $50 \%$. A number of works consider heterogeneous goods, typically models with monopolistic competition and product differentiation. Francois and Nelson (1998) find that a relative price shock has a far more moderate impact on the wage differential than in the standard homogeneous goods case. In a model including 12 countries and 64 differentiated production sectors, Smith (1999) finds that the impact of North-South trade on the European labour market is very limited. Cortes and Jean (1999) study the impact of a doubling of the size of the emerging economies on the European Labour Market and come up with a very moderate negative effect on the wage of the unskilled. In contrast to most other large-scale models, Nahuis (1999) finds that trade between OECD and non-OECD countries has a strong negative effect on the unskilled: about half of the rise in inequality results from this trade. Why his results differ so much from most other studies is difficult to trace, however.

\section{The Bottom Line}

Numerical analyses presume that the underlying model is "true" in some sense. Just how large and elaborate the model should be is open to debate. The precision of the quantitative results then depends on the calibration. The studies that have been undertaken on the basis of small-scale models suggest that trade may have had a significant but small effect on the wage differential and on employment. Studies based on large-scale models confirm this conclusion broadly. These studies indicate that the effects are milder, when product differentiation is taken into account. Studies based on small-scale models also indicate that rather small globalisation shocks suffice to drive economies into specialisation so that negative Stolper-Samuelson-effects on the unskilled are of limited size.

\section{Conclusion}

The attempts to identify and quantify the impact of technological progress and trade (globalisation) on relative factor prices and employment have not established a clear verdict. A majority of studies conclude that, compared with technological 
progress, globalisation has been of minor importance. However, some studies find very strong globalisation effects. Interestingly enough, strong globalisation effects have not only been identified in factor content studies, but also with regression analysis and in numerical studies.

This paper has attempted to trace the origins of such disparate results using the standard Jones trade model as unifying analytical backbone. Factor content analyses obtain strong globalisation effects, when a very low value is chosen for the aggregate elasticity of substitution or when the factor content of trade is calculated in a non-standard way. The variety of results obtained by regression analyses has its roots in the selection of industries, the measurement of skills and the choice of a so-called pass-through coefficient from technological progress into product prices. The diversity of results obtained by numerical analyses can be explained by the choice and scale of the model and its calibration.

Some researchers who have looked for trade effects concluded that technology must be it' when those trade effects found were small. Other researchers have reversed this procedure to obtain the opposite conclusion. Such inferencing is incorrect. Independent evidence is necessary in order to be supportive to any of the hypotheses. This conclusion is reinforced by the results emerging from consistency checks which indicate that the behaviour of key variables is determined by more than one type of shock.

Moreover, the paper shows that none of the four empirical methodologies is clearly superior: it takes several (special) assumptions to render the factor content approach compatible with HOS-theory; regression analyses typically involve an unsatisfactory passthrough assumption to allow for an influence of shocks on world prices; and numerical analyses simply take the underlying model as a correct description of reality. When several shocks occur simultaneously, all of the approaches have inference problems.

This leads to the conclusion that the ultimate judgement about the relative importance of trade and technology should be based on the results of all these empirical methodologies together rather than on any single on of these.

\section{Acknowledgements}

Comments and suggestions from Johannes Gebhard, Oliver Landmann and Jochen Michaelis are gratefully acknowledged. 


\section{References}

Abrego, L. and J. Whalley (2000), The Choice of Structural Model in Trade-Wages Decompositions. Review of International Economics, 8(3), 462-477.

Baldwin, R. E. (1994), The Effects of Trade and Foreign Direct Investment on Employment and Relative Wages. OECD Economic Studies 23, 7-54.

Baldwin, R. E. (1999), Inferring Relative Factor Price Changes from Quantitative Data. NBER Working Paper 7019.

Baldwin, R. E. and G. C. Cain (1997), Shifts in US Relative Wages: The Role of Trade, Technology and Factor Endowments. CEPR Discussion Paper 1596.

Bartelsman, R. E. and W. B. Gray (1996), The NBER Manufacturing Productivity Database. NBER Technical Working Paper 205.

Bhagwati, J. N. (1991), Free Traders and Free Immigrationists: Strangers or Friends? Working Paper 20. New York: Russell Sage Foundation.

Bhagwati, J. N. (1995), Trade and Wages: Choosing Among Alternative Explanations. Federal Reserve Bank of New York, Economic Policy Review 1, 42-47.

Bhagwati, J. N. (1998), Trade and Wages: A Malign Relationship? In: S. M. Collins (ed.), Imports, Exports, and the American Worker, Brookings Institution Press, Washington D.C., 49-99.

Bhagwati, J. N. and M. H. Kosters (eds.) (1994), Trade and Wages. Leveling Wages Down? The AEI Press. Publisher for the American Enterprise Institute, Washington, D.C.

Bhagwati, J. N. and V. H. Dehejia, (1994), Freer Trade and Wages of the Unskilled - Is Marx Striking Again? In: J.N. Bhagwati and M.H. Kosters (eds.) (1994), 36-75.

Bhagwati, J. N., A. Panagariya and T. N. Srinivasan (1998), Lectures on International Trade, $2^{\text {nd }}$ edition, MIT-Press.

Bliss, C. (2000), The Application of Toy Economic Models to the Analysis of Globalization. Nuffield College, Oxford, mimeo.

Borjas, G. J., R. B. Freeman and L. F. Katz (1992), On the Labor Market Effects of Immigration and Trade. In G.J. Borjas and R.B. Freeman (eds.): Immigration and the Work Force: Economic Consequences for the United States and Source Areas, University of Chicago Press, 213-244.

Borjas, G. J., R. B. Freeman and L. F. Katz (1996), Searching for the Effect of Immigration on Labor Markets, American Economic Review, $P \& P$ 86, 246-251.

Borjas, G. J., R. B. Freeman and L. F. Katz (1997), How Much Do Immigration and Trade Affect Labor Market Outcomes? Brookings Papers on Economic Activity 1(107), 190

Bound, J. and G. Johnson (1992), Changes in the Structure of Wages in the 1980s: An Evaluation of Alternative Explanations. American Economic Review, 82(3), 371-392. Burtless, G. (1995), International Trade and the Rise in Earnings Inequality. Journal of Economic Literature, 33, 800-816. 
Cline, W. R. (1997), Trade and Income Distribution. Institute for International Economics Washington, DC.

Collins, S. M. (1998a), Imports, Exports, and the American Worker, Brookings Institution Press, Washington D.C.

Collins, S. M. (1998b), Economic Integration and the American Worker: An Overview. In: S.M. Collins, Imports, Exports, and the American Worker, Brookings Institution Press, Washington D.C., 3-45.

Cortes, O. and S. Jean (1999), Does Competition from Emerging Countries Threaten Unskilled Labour in Europe? An Applied General Equilibrium Approach. In: P. Brenton and J. Pelkmans, Global Trade and European Workers, Macmillan Press Ltd, Houndsmills, Basingstoke, 96-122.

Deardorff, A. V. (2000), Factor Prices and the Factor Content of Trade Revisited: What's the Use? Journal of International Economics, 50, 73-80.

Deardorff, A. V. and D. S. Hakura (1994), Trade and Wages - What are the Questions? In: J.N. Bhagwati and M.H. Kosters (eds.), 77-107.

Deardorff, A. V. and R. W. Staiger (1988), An Interpretation of the Factor Content of Trade. Journal of International Economics 24, 93-107.

Feenstra, R. C. and G. H. Hanson (1996), Foreign Investment, Outsourcing and Relative

Wages. In: R.C. Feenstra, G.M. Grossman and D.A. Irwin (eds.), The Political Economy of Trade Policy: Papers in Honor of Jagdish Bhagwati. MIT-Press, Cambridge, 89-127.

Feenstra, R. C. and G. H. Hanson (1997), Productivity Measurement and the Impact of Trade and Technology on Wages: Estimates for the U.S., 1972-1990. NBER Working Paper 6052.

Fitzenberger, B. (1999), Wages and Employment Across Skill Groups. An Analysis for West Germany. Physica, Heidelberg.

Francois, J. F. and D. Nelson (1998), Trade, Technology, and Wages: General Equilibrium Mechanics. Economic Journal 108, 1483-1499.

Freeman, R. B. (1995), Are Your Wages Set in Bejing? Journal of Economic Perspectives 9, 15-32.

Harrigan, J. and R. A. Balaban (1999), U.S. Wages in General Equilibrium: The Effects of Prices, Technology, and Factor Supplies, 1963-1991. Mimeo. Federal Reserve Bank of New York.

Haskel, J. and M. J. Slaughter (1998), Does the Sector Bias of Skill-biased Technical Change Explain Changing Wage Inequality, NBER Working Paper 1940.

Haskel, J. and M. J. Slaughter (1999), Trade, Technology and UK Wage Inequality NBER Working Paper 2091.

Helpman, E. and P. R. Krugman (1985), Market Structure and Foreign Trade, The MITPress, Cambridge.

International Monetary Fund (1997), World Economic Outlook.

Jones, R. W. (1965), The Structure of Simple General Equilibrium Models. Journal of Political Economy 73, 557-572. 
Katz, L. F. (1992), Understanding Recent Changes in the Wage Structure. NBER-Reporter Winter 1992/93, 10-15.

Katz, L. F. and K. Murphy (1992), Changes in Relative Wages 1963-87: Supply and

Demand Factors. Quarterly Journal of Economics 107, 35-78.

Krueger, A. B. (1997), Labor Market Shifts and the Price Puzzle Revisited. NBER Working Paper 5924.

Krugman, P. (1995a), Growing World Trade: Causes and Consequences. Brookings Papers on Economic Activity 1:1995, 327-377.

Krugman, P. (1995b), Technology, Trade, and Factor Prices. NBER Working Paper 5355. Krugman, P. (2000), Technology, Trade, and Factor Prices. Journal of International Economics, 50, 51-71.

Krugman, P. and R. Z. Lawrence (1994), Trade, Jobs and Wages. Scientific American, April 1994, S.44-49.

Landmann, O. and M. Pflüger (1998), Verteilung und Außenwirtschaft. Verteilungswirkungen der Globalisierung. In: B. Gahlen, H. Hesse, H. J. Ramser (eds.), Verteilungsprobleme der Gegenwart. Diagnose und Therapie. Tübingen, Mohr Siebeck, 127-157.

Lawrence, R. Z. (1994), The Impact of Trade on OECD Labor Markets. Occasional Papers No.45, Group of Thirty, Washington, DC, 1994.

Lawrence, R. Z. (1996), Single World, Divided Nations? International Trade and OECD Labor Markets. Brookings Institution Press. OECD Development Centre Paris 1996. Lawrence, R. Z. and C. L. Evans (1996), Trade and Wages: Insights from the Crystal Ball. NBER-Working Paper 5633.

Lawrence, R. Z. and M. J. Slaughter (1993), International Trade and American Wages in the 1980s: Giant Sucking Sound or Small Hiccup? Brookings Papers on Economic Activity, Microeconomics, 2, 161-226.

Leamer, E. E. (1994), Trade, Wages and Revolving Door Ideas. NBER Working Paper 4716.

Leamer, E. E. (2000), What's the Use of Factor Contents? Journal of International Economics, 50, 17-49.

Leamer, E. E. (1998), In Search of Stolper-Samuelson Linkages between International Trade and Lower Wages. In: S.M. Collins (ed.), Imports, Exports, and the American Worker, Brookings Institution Press, Washington D.C., 141-203.

Murphy, K. and F. Welch (1991), The Role of International Trade in Wage Differentials. In: M.H. Kosters (ed.), Workers and their wages: Changing patterns in the United States, AEI-Press, Washington D.C., 39-69.

Nahuis, R. (1999), Global Integration and Wages in a General Equilibrium World Model: Contributions of WorldScan. In: P. Brenton and J. Pelkmans, Global Trade and European Workers, Macmillan Press Ltd, Houndsmills, Basingstoke, 123-146.

Neven, D. and C. Wyplosz (1999), Relative Prices, Trade and Restructuring in European Industry. In: M. Dewatripont, A. Sapir and Kh. Sekkat, Trade and Jobs in Europe. Much Ado About Nothing?, Oxford University Press, 33-59. 
OECD (1997), Employment Outlook. July 1997, Paris.

Panagariya, A. (2000), Evaluating the Factor-Content Approach to Measuring the Effect of Trade on Wage Inequality. Journal of International Economics, 50, 91-116.

Pflüger, M. (2001), Trade, Capital Mobility, and the German Labour Market. Weltwirtschaftliches Archiv, 137(3), 473-497.

Sachs, J. D. and H. J. Shatz (1994), Trade and Jobs in U.S. Manufacturing. Brookings Papers on Economic Activity 1, 1-84.

Sachs, J. D. and H. J. Shatz (1998), International Trade and Wage Inequality in the United States: Some New Results. In: S.M. Collins (ed.), Imports, Exports, and the American Worker, Brookings Institution Press, Washington D.C., 215-254.

Slaughter, M. J. (1998a), What are the Results of Product Price Studies and What Can We Learn from Their Differences? NBER Working Paper 6591.

Slaughter, M. J. (1998b), International Trade and Labour Market Outcomes: Results, Questions, and Policy Options, Economic Journal, 108, 1452-1462.

Smith, A. (1999), The Labour Market Effects of International Trade: A Computable General Equilibrium Model. In: M. Dewatripont, A. Sapir and Kh. Sekkat, Trade and Jobs in Europe. Much Ado About Nothing?, Oxford University Press, 95-112.

Wood, A. (1994), North-South Trade, Employment and Inequality. Oxford, 1994.

Wood, A. (1995), How Trade Hurt Unskilled Workers. Journal of Economic Perspectives 9, 57-80.

Wood, A. (1998), Globalisation and the Rise in Labour Market Inequalities. Economic Journal 108, 1463-1482. 


\section{Appendix: The $R D$ curve}

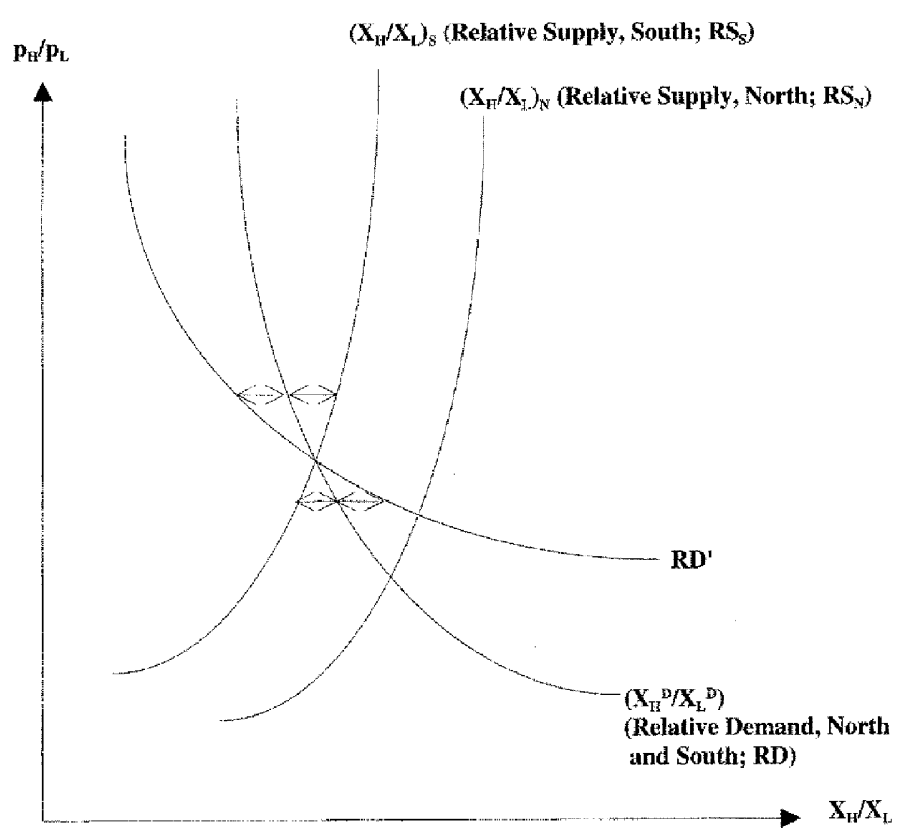

$R D$ is obtained by adding the net relative supply of the South $\left(R D-R S_{S}\right)$ to the relative demand of the North $R D$ at each level of relative prices. Note that with technological progress occuring only in the North (as assumed in the discussion in section 2), the only curve affected is $R S_{\mathrm{N}}$ (Landmann and Pflüger 1998). 